\title{
The Implementation of Concrete Areas of the Community Organization Councils for self-governance of Local Communities: A Case studies of the community organization councils in Na Wae Sub-district, Chawang District, Nakhon Si Thammarat Province Thailand.
}

\author{
Udomsak dechochai ${ }^{1}$, Utit Sangkharat ${ }^{2}$, Wanchai Dhammasaccakarn ${ }^{3}$ \\ ${ }^{1} \mathrm{Ph} . d$ (candidate) of Prince of Songkla University Thailad \\ ${ }^{2}$ Asst.Phrof.Dr.,Prince of Songkla University Thailand \\ ${ }^{3}$ Assoc.Phrof.Dr., Prince of Songkla University Thailand \\ ${ }^{1}$ dibjand@gmil.com, ${ }^{2}$ utit.s@psu.ac.th 1, ${ }^{3}$ dh_wanchai@yahoo.com
}

\begin{abstract}
This article is a part of research study on The Implementation Of the Community Organization Councils for self-governance: A Case studies of community organizations councils in Nakhon Si Thammarat Province Thailand, Which aims to study the Implementation of Concrete Areas of the community organization councils To promote self-governance knowledge of local communities The researcher gave an example of the community organization councils in Na Wae Sub-district, Chawang District, Nakhon Si Thammarat Province Thailand. Which is the prototype area of this research By using participatory action research methods. The results of the research onThe Implementation of Concrete Areas of the Community Organization Councils for self-governance of Local Communities: A Case studies of the community organization councils in Na Wae Sub-district, Chawang District, Nakhon Si Thammarat Province Thailand found that It is a platform for sharing knowledge and experiences among development partners, including government, private and public sectors who are members of community organizations, which have a number of driving activities, both on issues, problems and social capital such as customs and traditions, community services, community rights in resources and environment, organic farming systems in the community, community welfare fund systems, and Community financial institutions etc. And There are new community organizations According to the policy of the agency And government policies such as civil servant shops, Rural Solidarity Group etc. and It is an important strategy to Implementation the community organization council for selfgovernance in the future. This will be the growth and strength of the Thai citizen movement to another level.
\end{abstract}

Keywords

The Implementation of Concrete Areas, the Community Organization Councils, self-governance of Local Communities.

Article Received: 10 August 2020, Revised: 25 October 2020, Accepted: 18 November 2020

\section{Introduction}

The Community Organization Council was born from the Community Organizations Council Act B.E. 2551 (2008) which has important principles in promoting local communities of the country. Able to Set up a group of community organizations according to their own issues in each area. By jointly establishing solutions and processes for solving problems To make a proposal to the government Both local and national levels And is an important practice in promoting self-governance of local communities In particular, according to Article 21[ 1], The Community Organization Council. The mission is as follows. That is, promote and support community organization members to preserve or restore local wisdom traditions. Arts or culture of the community and the nation By creating cooperation with local government organizations and government agencies to manage, Maintenance And the utilization of natural resources that will benefit the community and the nation for sustainability. Along with disseminating and giving knowledge and understanding to members of the community organization Including cooperation in environmental quality protection, etc.[2] And as Kovit Puang-ngam [3] proposed the self-governance of local communities in 5 different dimensions: 1] self-management of local communities in the area of community plan. 2] Selfgovernance of local communities in agriculture 3] Self- governance of local communities in terms of natural resources and environment 4] self-governance of local communities in community finance 5] self-governance of local communities in terms of sufficiency economy.

Therefore, the mobilization of community organization councils has been implemented to create concrete areas, self-governance of local communities in the area of $\mathbf{2 , 9 5 3}$ sub-districts with intensive operations of about $\mathbf{3 0 0}$ subdistricts nationwide. With the preparation of spatial data Organize a self-analysis process To create a local community plan for self-governance, short, medium, long, creating a collaborative mechanism at the local level. Including the participation of the lower base community by providing a forum at the district level. By community organization council Including a network of community organizations is an important mechanism in driving To formulate a plan for the development of self-governance reforms that are consistent with the context of the area.[ 4 ] And if since the Community Organizations Council Act B.E. 2551 (2008) is in effect until the year 2019 [ 5 ] Found that the effect of the mobilization It was formed as a concrete area for the community organization council, leading to the self-governance of 518 sub-districts Scattered throughout all regions of the country And there is an ongoing operation plan to achieve the goals set. According to the 5-year community organization council (2018-2022) strategic plan 
It is extremely interesting that The Implementation of Concrete Areas of the Community Organization Councils for self-governance of Local Communities: A Case studies of the community organization councils in Na Wae Subdistrict, Chawang District, Nakhon Si Thammarat Province, Thailand. This is an area that plays an important role in The Implementation of the community organization council for self-governance of Local Communities. In particular, the forum of the community organization councils is a tool to promote knowledge for self-governance of local communities and as a model concrete area for other community organization councils in the future.

\section{Objectives}

To study the Implementation of Concrete Areas of the community organization councils To promote selfgovernance knowledge of local communitie

\section{Methodology}

This research study. The researcher used participatory action research methods Or often referred to as "PAR". The study was divided into 2 main features in order to make the study results more complete as follows.

1. Research studies from documents, By studying from academic documents, research results, thesis articles and other evidences Related both within the country and abroad To help fill in the construction of a theoretical conceptual framework for the researcher This can be said to be an important part of this research process.

2. Field research studies to The Implementation of Concrete Areas of the Community Organization Councils for selfgovernance of Local Communities: A Case studies of the community organization councils in $\mathrm{Na}$ Wae Sub-district, Chawang District, Nakhon $\mathrm{Si}$ Thammarat Province Thailand. It is a part of research study on The Implementation Of the Community Organization Councils for self-governance A Case studies of community organizations councils in Nakhon Si Thammarat Province Thailand, The researcher coordinated with the community organization council steering committee, namely 1] Chairman of the Steering Committee of Nakhon Si Thammarat Provincial Community Organization Council 2] Secretary-General of the Steering Committee of Nakhon Si Thammarat Provincial Community Organizations Council 3] 5 staff members of the Community Organization Development Institute (Public Organization), By organizing a community forum with representatives of committee steering the community organization council, Na Wae Subdistrict, Chawang District, Nakhon Si Thammarat Province And members of the community organization council of 12 villages shared knowledge and experiences These consist of 1] Chairman of the $\mathrm{Na}$ Wae Sub-district Community Organization Council 2] Secretary of the Na Wae Subdistrict Community Organization Council 3] Chairman of the Na Wae Sub-district Administrative Organization 4] Representatives of 12 members of the $\mathrm{Na}$ Wae Community Organization Council

\section{Results}

The Implementation of Concrete Areas of the Community Organization Councils for self-governance of Local Communities: A Case studies of the community organization councils in $\mathrm{Na}$ Wae Sub-district, Chawang District, Nakhon Si Thammarat Province, Thailand. Found that :

1. The Implementation of the Community Organization Councils for self-governance.

The Community Organization Councils of Na Wae Subdistrict, Chawang District, Nakhon Si Thammarat Province Started registration and established around December 2009 under of the Community Organization Councils Act B.E.2551 (2008) with members who represent community organizations. Covering 12 villages with approximately 2,394 households. The community organizations There are a number of common activities in social driving, both in issue and social capital. such as customs and traditions, community services, community rights in resources and environment, organic farming systems in the community, community welfare fund systems, and Community financial institutions etc. Especially The establishment of a community financial institution spanning all 12 villages can be said to drive the social capital together of the $\mathrm{Na}$ Wae Sub-District Community Organization Council. Which is a concrete present And There are new community organizations According to the policy of the agency And government policies such as civil servant shops, Rural Solidarity Group etc.

2. Using the community organization council as is a forum for the community meeting to promote knowledge in selfgovernance.

Na Wae Sub-district Administrative Organization, Chawang District, Nakhon Si Thammarat Province found that There are approximately 34 community organization groups scattered in the Na Wae Sub-district, Cover area 12 villages, which have been established and registered as members of the Na wae Sub-district Community Organization Council. According to the Community Organizations Council Act B.E. 2551 (2008) Therefore, the $\mathrm{Na}$ Wae Community Organization Council has the status that is certified under the Act Able to connect groups of community organizations which are driven by various issues Of the district together Thus creating a space for coordination between the state and the community Both the owner of the problem and the contributors in solving the problem. And also found that the $\mathrm{Na}$ Wae Community Organization Council There is a community forum to meet members of the community organization council once a month Which the local government agencies and provincial officials and various support staff Able to participate in exchange and learn experiences And set ways to solve problems together Causing the movement of the community organization council in unity And to promote the self-governance knowledge of the committee And a member of the community organization council in $\mathrm{Na}$ Wae Sub-district, Chawang District, Nakhon $\mathrm{Si}$ Thammarat Province Especially in the area of community benefits as a key component in the self-governance of local communities. And it will be knowledge that can be passed on to members of the community and those who are interested. 


\section{Discussion}

The Implementation of Concrete Areas of the Community Organization Councils for self-governance of Local Communities: A Case studies of the community organization councils in $\mathrm{Na}$ Wae Sub-district, Chawang District, Nakhon Si Thammarat Province, Which aims to study the Implementation of Concrete Areas of the community organization councils To promote selfgovernance knowledge of local communities When considering that $\mathrm{Na}$ wae Community Organization Council There are a number of common activities in social driving, both in issue and social capital. To enhance self-governance of local communities And the $\mathrm{Na}$ Wae Community Organization Council Having the status that has been certified under the Community Organization Council Act B.E. 2551 (2008) Especially driving the mission under Article 21 of The Community Organization Council Act As Phanthip Phet Mak [6] summarized 8 conditions for selfgovernance of local communities 1] Using the social capital base 2] solving common problems of local people 3] Data preparation as a tool to drive work 4] Use of development indicators as a tool for monitoring development results. 5] The good relationship base between local communities has a common goal. 6] Having a community organization council is a central forum for regular consultations. 7] Opening space for young leaders 8] Coordinating with external agencies to work.

The Na wae Community Organization Council There is a community forum for meeting members of the community organization council together. When considering that It promotes knowledge of the committee for self-governance. And a member of the community organization council in $\mathrm{Na}$ Wae Sub-district, Chawang District, Nakhon Si Thammarat Province This will be knowledge that can be passed on to members of the community and interested people and is an important tool for self-governance of the local community.

\section{Conclusion And Suggestion}

It can be concluded that The Implementation of Concrete Areas of the Community Organization Councils for selfgovernance of Local Communities: Case Study of Community Organization Council of Na Wae Sub-district, Chawang District, Nakhon Si Thammarat Province Use a community organization council as a forum To promote knowledge Share experiences together of community organizations and Various support networks to contribute to the main goal of self-governance of local communities. However, in order to The Implementation of Concrete Areas of the Community Organization Council for the selfgovernance of local communities Is sustainable Therefore, there are additional suggestions as follows

1. The Community Organization Council of Na Wae Subdistrict, Chawang District, Nakhon Si Thammarat Province Should monitor and evaluate the driving results of community organizations By creating data sets such as project activities Performance results, problem conditions and ways to improve, etc. To summarize as a lesson and use as a guideline for the operation of community organizations. 2. Development parties Both public and private sectors should be used The community forum of the community organization council for as a tool to exchanging knowledge, And considering the budget to support community projects Including driving other missions of the agency, etc.

3. The $\mathrm{Na}$ wae Community Organization Council Must develop and upgrade the driving mechanism to be strengthened From the inside of the community organization council, such as creating participation, cooperation, public awareness Support to strengthen community organization groups That arise from the diverse resource base and community capital, etc. to reduce dependence on the Act and external resources

4. Community organization group Which performs each type of activity should be presented A group action plan once a year, To the meeting of the community organization council For the exchange knowledge together Both operations And evaluation To lead to a lesson summary together

\section{Acknowledgment}

Thanks to the Chairman of the Community Organization Council, Na Wae Sub-district, Chawang District, Nakhon Si Thammarat Province Thailand. Representative of the Community Organization Committee, Chairman of the $\mathrm{Na}$ Wae Sub-district Administrative Organization, With all members and staff involved, including experts and advisors of this research paper.

\section{References}

[1] Community Organizations Development Institute (Public Organization), "Community Organizations Council Act B.E. 2551 (2008)" Community Organizations Development Institute (Public Organization) printing Bangkok Thailand,2008.

[2] Udomsak dechochai, Utit Sangkharat, and Wanchai Dhammasaccakarn, "The context of the implementation of $\mathrm{Na}$ Wae Subdistrict Community Organization Council to self-governance community Under the constitution of Thailand 2017', on MCU Nakhondhat, Vol.6, No.10,pp.2 December 2019.

[3] Kovit Puang-ngam, "Self-Governance of the community and local, (1st edition), Printing house Thammasat University Book Center,Bangkok,Thailand,2010.

[4] Community Organization Development Institute (Public Organization), "Meeting documents Assembly of community organization networks Upholding local communities and partners for self- 
Governance and the 1st National Conference of the Tambon Community Organization Council, 2011 (first edition), Company Viscom Center Co., Ltd,Bangkok, Thailand, 2011.

[5] Community Organization Development Institute (Public Organization), "Annual report 2019", Ministry of Social Development and Human Security,Bangkok, Thailand,2020.

[6] Phanthip Phet Mak, "Meeting documents Assembly of community organization networks Upholding local communities and partners for self-Governance and the 1st National Conference of the Tambon Community Organization Council, 2011 (first edition), Company Viscom Center Co., Ltd,Bangkok, Thailand, 2011. 